\section{The past is the key to the present?}

\section{Janet V. Watson}

Precambrian of the Southern Hemisphere. Developments in Precambrian Geology, 2. Edited by D.R. Hunter. Pp.882. ISBN 0-444-41862-8. (Elsevier Scientific: 1981.) $\$ 170.75$, Df1 350 .

THE discovery, a decade or so ago, that the crustal regime that controls present-day geological processes operates on a worldwide scale gave earth scientists a muchneeded push towards thinking of rock structures in terms of large, simple patterns. This approach worked well for the oceanic crust, where the scale of the magnetic striping matches that of the ocean basins themselves. But the continents are another matter. The time-span of continental evolution is more than ten times that recorded in oceanic crust and the continental crust is a patchwork of units formed during different periods in response to entirely different controls.

Thus every land-based geologist has at some time come up against the problem of how to make sense of a complex terrain in regional or global terms without doing violence to the evidence of his own eyes. The authors of this book have tackled the problem with remarkable success - they have at once produced a work of reference which will stand for many years to come and revealed new patterns and relationships on a continental scale. If it is true that a child's first seven years set the pattern for the rest of its life, it must surely be true that the fundamental features of the continental crust were built into it in Precambrian times. One of the fascinations of the book is that although Phanerozoic events such as the development of the African rift valley are not dealt with directly, they are foreshadowed in accounts of structures formed two billion years earlier.

The scene is set in an editorial introduction and in three admirable chapters introducing the sections on Australia, Africa south of the equator and South America. A welcome feature, seen especially in the contributions by R.W.R. Rutland and by D.R. Hunter and D.A. Pretorius, is the integration of geophysical and geological data to document the extent and boundary relations of successive tectonic provinces. These readable and thought-provoking chapters establish the large-scale structural patterns which must be explained in any global hypothesis of crustal evolution. The details are filled in by chapters which deal, area by area, with succession, structure, magmatism and mineralization. Sedimentary environments and palaeontology (often neglected by Precambrian geologists) take their place alongside the more traditional aspects. Although it would be idle to claim that all of these chapters make easy reading, there are abundant rewards. The long familiarity of the various authors with their areas and their self-denial with respect to theoretical hobby-horses give authority to the text, which covers areas such as Zimbabwe that have profoundly influenced our understanding of the Precambrian crust. The juxtaposition of apparently unrelated observations gives unexpected insights into the connections between older and younger structures, or between magmatism and basin formation - I particularly liked A.D.T. Goode's suggestion that certain types of Archaean belt seem destined to remain unstable.

The supercontinent of Gondwanaland has been crucial to thoughts on continental drift for more than 60 years. Alex du Toit, that wisest Gondwanaland geologist, gave a third of his Geology of South Africa to the Precambrian at a time when it was customary to dismiss pre-Phanerozoic events in a page or so. Now, Dr Hunter and his colleagues have built up the Precambrian picture into a coherent whole. The lion's share of the book rightly goes to Australia and Africa. India excluded itself long ago by drifting into the Northern Hemisphere, South America receives somewhat cursory treatment and Antarctica is, rather sadly, omitted. But the core of the Gondwanaland story is now there for all to read. Du Toit would surely have approved.

Janet $V$. Watson is a Professor in the Department of Geology at Imperial College. University of London.

\title{
Mixed relations between yeasts and man
}

\section{James A. Barnett}

Biology and Activities of Yeasts. The Society for Applied Bacteriology Symposium Series, No. 9. Edited by F.A. Skinner et al. Pp.310. ISBN 0-12-648080-X. (Academic: 1981.) £15.80, \$38.

RightLY, for a symposium of an "applied" society, half of the chapters in this book concern industrial problems. There are remarkable yeasts that can ferment honey of $\sim 80 \%$ hexose, and Tilbury's careful review of such yeasts that tolerate high concentrations of sugar or salt is particularly welcome. Unfortunately, Davenport's survey of cold-tolerant yeasts is not comparable; such is still needed, even if only to summarize the physiological research required to solve current industrial problems. Writing on spoilage, Seiler (bakery products) and Dennis and Buhagiar (fruit and vegetables) bring out the anecdotal character of many "applied" studies: even when researchers trouble to identify the yeasts properly, often no physiological work on their role is undertaken. An exception is the last author's work on the breakdown of cellulose of rhubarb by Trichosporon species.

There are brief, helpful, summaries of work on the flocculation and ethanol tolerance of Saccharomyces cerevisiae (Rose). Put and de Jong review the heatresistance of yeasts that spoil soft drinks and other products of fruits. In addition, laymen should be grateful for two authoritative medical articles: Hurley describes the increasingly recognized importance of infections by yeasts of the genus Candida, while Campbell and Mackenzie give an admirably concise up-to-date survey of Cryptococcus neoformans.

Three chapters are taxonomical, but more for taxonomists than for applied microbiologists. For example Kreger-van $\mathrm{Rij}$ (generic differences) complains, reasonably enough, about abolishing Torulopsis and, elliptically, expresses disapproval of the new genus Hormoascus. According to von Arx, yeasts are deficient moulds and, if the wicked twentiethcentury microbiologist, Kluyver, hadn't got his hands on them, yeasts would now be properly classified, according to their anatomical structures and the strict legal rules of Botanical Nomenclature. Both of these taxonomists, and also van der Walt, in his excellent discussion of delimiting species, believe in phylogenetic classification and are reverent towards such measurements as " $\% \mathrm{G}+\mathrm{C}$ ", ignoring possible differences in rates of evolution of DNA base composition. These subjects, suitable for private intercourse between consenting taxonomists, were perversely selected for this symposium: taxonomic problems in applied work are chiefly those of identifying, not classifying, yeasts.

Furthermore, although the editors boast of this volume as a "comprehensive review of the biology and activities of yeasts", they omit the genetic (nuclear and mitochondrial) and physiological control of metabolism, as well as other current research of potential industrial interest, such as genetic manipulation by protoplast fusion and recombinant DNA techniques, and also $\mathrm{C}_{1}$-metabolism.

Most of this symposium should be useful to teachers of microbiology, and specialists may be interested in certain articles, notably those on taxonomy and "xerotolerant" yeasts. Accordingly, the book should be in university and technical college libraries, as well as in those serving institutes for applied research where yeasts are studied.

James A. Barnett, employed by the Agricultural Research Council, is honorary lecturer in the School of Biological Sciences at the University of East Anglia. 